\title{
A Ciência atrás da siderurgia e da mineração do ferro
}

\section{THE SCIENCE BEHIND STEELMAKING AND IRON MINING}

\author{
Pedro Wagner Gonçalves ${ }^{1}$, Natalina Aparecida Laguna Sicca ${ }^{2}$, Maurílio Antonio Ribeiro Alves ${ }^{3}$, Maria Cristina da Silveira Galan Fernandes ${ }^{4}$ \\ 1 - Programa de Pós-Graduação em Ensino e História de Clências da Terra. Instituto de Geociências. Universidade Estadual de Campinas. \\ 2 -Faculdade de Filosofia Ciências e Letras, Universidade de São Paulo. Campus de Ribeirão Preto. (aposentada). \\ 3 - Departamento de Biologia. Universidade de São Paulo. Campus Ribeirão Preto (aposentado). \\ 4 - Departamento de Educação. Universidade Federal de São Carlos.

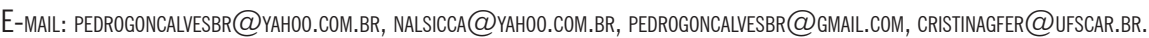

Abstract: The lack of Earth Sciences teaching in $\mathrm{K} 12$ level in Brazil is the reason to investigate how to improve the curricular integration and the teacher education for Earth Sciences. We search for data sets can facilitate an science projects for teacher education and innovative curricula to promote the knowledge of the Earth and the environment. In this article, we present the case study about integrated course using the data from history of science and technology of iron and steel mining, manufacture and origin in the terrestrial crust. Teachers of chemistry have done this course and they have became able to teach their students from other point of view (they change their ideas about nature, geologic time and the environment). Teachers acknowledge the different scales of time and its implications to social and environmental processes that drive the changes affecting Earth's resources (time scales and global climate changing). These courses has been positive, with participants indicating changes in their practical experience and view on natural resources. This encourages the teaching and learning perspective with curricular integration.
Manuscrito:

Recebido: 28/12/2018

Corrigido: 04/jul/2019

Aceito: $21 / 08 / 2019$

Citação: Gonçalves, P. W.; Sicca, N. A. L.; Alves, M. A. R.; \& Fernandes, M. C. S. (2019). A Ciência atrás da siderurgia e da mineração do ferro. Terræ Didatica, 15, 1-8, e19030. doi:10.20396/td.v15i0.8654167

Keywords: Earth System Science, Global environmental change, Curriculum integration, Teacher education, History of science, mining of iron.

\section{Introdução}

A região de Ribeirão Preto, Estado de São Paulo, foi intensamente ocupada somente no último quartel do século XIX. Marcada por intensa disputa de terras entre famílias rivais, acabou se constituindo por meio de um acordo com a participação da Igreja.

Passado esse episódio mais conflituoso, teve rápido crescimento agrícola promovido pela produção de café. Tornou-se, ainda nos oitocentos, um dos centros mais importantes de produção mundial de café. A concentração fundiária e financeira criou condições favoráveis à diversificação da aplicação do capital. Primeiro, abriu espaço para expansão da rede ferroviária (atividade diretamente associada ao transporte do café para exportação). À medida que se esgotaram tais possibilidades, novos empreendimentos foram realizados (empresas de produção de energia elétrica, distribuição de água etc. para as áreas urbanas).

Esta é uma história recente, mas fragmentada e incompleta.
Diante desse quadro, um grupo de professores do ensino básico procurou identificar ruínas de estações e ramais ferroviários, sedes e outras construções de antigas fazendas (hoje dispersas na malha urbana). Nesse esforço para recuperar o patrimônio histórico, cultural e natural do município, foram identificadas as ruínas de uma usina/ empresa siderúrgica que operou há quase cem anos atrás e da qual só uma pequena parcela da população tem conhecimento.

A Companhia de Força e Luz criou a Eletro-Metalúrgica Brasileira e construiu a Usina Epitácio Pessoa com infraestrutura necessária para produção de ferro e aço a partir de itabiritos explotados em São Sebastião do Paraíso (Estado de Minas Gerais). Isso incluiu compra de empresas, ramais e estações ferroviárias, de terrenos e fazendas. Passados menos de uma década, a siderúrgica faliu como a maioria dos empreendimentos siderúrgicos daquela época.

Os elementos que foram recuperados dessa história serviram de mote para explorar diversos aspectos científicos e técnicos, bem como abriram 
caminho para o entendimento da história geológica da região principalmente por meio dos processos de concentração do minério de ferro.

Neste texto, expomos como as questões de história regional se tornaram o foco de um processo de ensino das Ciências da Terra e passaram a ser módulo para formação continuada de professores.

\section{Objetivos}

Nosso objetivo neste estudo é descrever um módulo de formação continuada de professores dedicado às transformações do material ferro na Terra e no universo (Ferro: do Sol aos objetos de metal - A Ciência atrás da siderurgia e da mineração do ferro). Procuramos reunir evidências que o módulo está alinhado com os princípios curriculares do Grupo de Pesquisa "Interdisciplinaridade e Ciência do Sistema Terra como Eixos para o Ensino Básico".

\section{Construção de uma perspectiva de Ciência do Sistema Terra por meio da interação dos professores voltados para a integração curricular}

No final do mês de janeiro de 2018, o Ministério da Educação (MEC) divulgou os dados do Censo Escolar de 2017. O ensino médio foi oferecido para 8 milhões de estudantes e o ensino fundamental a mais de 48 milhões de alunos. Nessa escala, o desenvolvimento do Ensino de Geociências encontra fortes obstáculos em virtude das políticas curriculares que regem os níveis de educação básica e da formação de professores no Brasil. Em outros termos, não mais do que algumas dezenas de milhares desses estudantes recebeu uma formação estruturada em Ciências da Terra. ${ }^{1}$

Esse campo só existe como disciplina para pouco mais de algumas centenas de escolas das

$1 \quad$ Adota-se a nomenclatura de Gimeno Sacristán sobre as modalidades de currículo. Gimeno (2000) classificou currículos em: prescrito (dispositivo legal que instaura o que deve ser ensinado), planejado (organizado pela indústria cultural na forma de livros kits, etc. para orientar o trabalho dos professores), em ação (desenvolvido pelos professores de acordo com as características de seus alunos, é o espaço para o desenvolvimento de políticas microcurriculares), avaliado. O que é necessário assinalar aqui é que, desde 1961, a legislação brasileira eliminou componentes curriculares diretamente vinculados aos estudos da Terra (esses existiram como disciplina obrigatória do ensino secundário das legislações anteriores). mais 180.000 unidades escolares de nível básico que existem no País. ${ }^{2}$

No início do século XXI, promovemos uma iniciativa voltada para preparar professores para implementar Ciências da Terra. Selecionamos um grupo de voluntários especialmente capacitados em termos de experiência profissional e iniciativa para

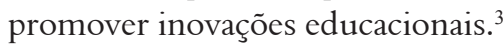

Propusemos a eles o apoio para interação, troca de experiências e aporte em torno de três eixos: Ciência do Sistema Terra, políticas curriculares e formação continuada de professores. Explicamos que seríamos ferrenhos defensores da ideia de autonomia do professor para elaborar micropolíticas curriculares por meio das quais os professores deveriam coletivamente decidir o que e o como ensinar, teriam a possibilidade de discutir porque ensinar e seriam os responsáveis por avaliar seus alunos (Gonçalves \& Sicca, 2008).

Uma condição era essencial para quem quisesse participar: implementar Ciências da Terra por meio de aproximações com a escala do tempo geológico. ${ }^{4}$

2 As políticas curriculares vigentes no Brasil acompanham ampla gama de países que desprezam os estudos da Terra e do ambiente. Apesar dos argumentos consistentes presentes em Carneiro, Toledo e Almeida (2004) em defesa da inclusão das Ciências da Terra no nível básico; apesar da demonstração conduzida por Lacreu (2009) revelando o papel de conscientização ambiental dos conteúdos das Ciências da Terra (e seus nexos com a alfabetização em Ciências da Terra); apesar do esforço de sintetizar os dez temas centrais para o ensino da Ciência do Sistema Terra da Espanha (Pedrinaci et al., 2013) nada alterou a situação de ausência curricular desse campo de conhecimento na educação brasileira.

3 Todos os professores participantes trabalham na rede pública de ensino da área urbana de Ribeirão Preto, Estado de São Paulo. A clientela envolve alunos de distintos níveis sociais e culturais, muitas escolas apresentam baixos níveis de aprendizagem e rendimento. As unidades escolares são semelhantes aos problemas descritos por Johnson, Kahle \& Fargo (2009) sobre o círculo vicioso de professores mal preparados e baixos níveis de rendimento acadêmico de escolas urbanas. Embora as iniciativas realizadas sejam diferentes das opções do citado artigo, buscou-se enfrentar o problema de ensino e aprendizagem.

$4 \quad$ Naquele momento, um alvo era central para sustentar a proposição: a necessidade de alfabetização em Ciência do Sistema Terra e sua contribuição para uma perspectiva mais realista de alfabetização ambiental (ver Mayer, 2002). Gonçalves (2001) associou alfabetização científica à formação continuada de professores para as Ciências da Terra. 0 projeto vinculou conceitos chaves dos estudos da Terra (dinâmica de ciclos, fluxos e processos; tec- 
O processo que foi instaurado construiu pontes e colaborações. Professores cuja formação inicial era muito diversificada (Biologia, Física, Geografia, História, Matemática, Química, Sociologia) buscaram temas, tópicos e conceitos que pudessem aproximar e amalgamar diferentes campos. $\mathrm{O}$ fio condutor em termos conceituais foi o tempo geológico (muitas referências colocam o tempo geológico como particularidade central dos estudos da Terra, desde os trabalhos de História da Ciência de Rossi, 1984 a Cervato \& Frodeman, 2014). ${ }^{5}$ Isso conduziu a um esforço de construir eixos curriculares integradores por meio de políticas microcurriculares voltadas para formar professores e promover conceitos importantes que caracterizam as Ciências da Terra e, ao mesmo tempo, promovem a integração curricular em torno de estudos ambientais do local e da cidade (Sicca et al., 2014).

Em outros termos, a ausência de Ciências da Terra, Ciências Ambientais e da Terra, Geociências, História Natural etc. dos currículos prescritos na educação brasileira implicou um esforço no Grupo de Pesquisa de integração curricular focalizando principalmente o tema tempo geológico.

Ao longo dos anos os resultados foram os melhores: professores encontraram pontos de convergência entre Biologia, Geografia e Matemática; Biologia, Geografia, História e Matemática; Matemática e Química etc. De certo modo, a formação continuada de professores de larga duração corresponde ao que Shipley et al. (2017) afirmam sobre integração de teoria e prática que caracteriza o Grupo de Pesquisa em Educação de Geociências dos EUA: a pesquisa continuada realizada em Ribeirão Preto mostra a integração da pesquisa educacional com a prática de ensino realizada nas escolas. Adicionalmente à proposta de Shipley et al. (2017) - de encontrar pontos nas disciplinas que revelem o potencial das Ciências da Terra para o desenvolvimento transdisciplinar - foi atingida de diferentes formas a organização de projetos didáticos para o ensino básico.

tônica de placas; movimentos das esferas fluidas) aos modos de selecionar e organizar conteúdos, ou seja, a ideia de natureza das Ciências da Terra tomou a História e Filosofia da Ciência como fundamentos relevantes da alfabetização científica (ver Gonçalves, 1997).

5 Levantamento exploratório revelou que a concepção de ambiente veiculada pelos professores de Ciências era muito limitada e largamente reproduzia ideias do senso comum veiculadas pela mídia (ver: Gonçalves \& Sicca, 2005a).
Desde os primeiros momentos, professores decidiram adotar como eixo curricular o local e a cidade, ou seja, selecionaram pontos, problemas, características da cidade como alvo de estudo e pesquisa (conduzida pelos professores junto com seus alunos). Estes serviram como pontos de partida e intersecção de distintos campos do conhecimento. ${ }^{6}$

Outro eixo curricular chave foi o caminho do local e da cidade para conceitos universais que perseguiram a expansão da escala de tempo (do tempo vivido, ao histórico e daí para o tempo profundo de milhares a milhões de anos) - a questão foi tratada por Gonçalves \& Sicca (2005b).

Um terceiro eixo curricular foi a busca dos caminhos e das origens. Isso esteve presente para explicar os fluxos de pessoas e mercadorias, mas se expandiu para dar conta dos fluxos de matéria e energia dos processos geológicos. A formalização desses passos ocorreu ao se adotar a teoria de sistemas como eixo curricular e esta passou a ser usada sob o ponto de vista do tempo geológico.

O eixo relativo a estudar, pesquisar e transformar em alvo de estudo o local e a cidade foi acompanhado pelo uso do trabalho de campo. Trata-se de um exercício típico do trabalho geológico (especializar informações, interpretar a partir de registros codificados, colher dados para classificação e organização posterior etc.). Este eixo curricular ajudou os professores a incorporar hábitos dos profissionais da Geologia, ou seja, ao iniciar um tema colhem dados no campo, organizam espacialmente por meio da linguagem visual, representam os conceitos usando quatro dimensões (o espaço tridimensional e o tempo).

Ao mesmo tempo, o eixo vinculado ao local e à cidade intrinsecamente põem questões que dificilmente podem ser tratadas sem recorrer a uma combinação de estudos, pesquisas e reflexões que requerem múltiplas dimensões. Nessa etapa, Ciência do Sistema Terra é especialmente rica para abrir possibilidades, nexos e revelar caminhos que inter-relacionam as dimensões por meio dos campos de conhecimento disciplinares. Ao tratar isso, sob uma abordagem investigativa,

$6 \quad$ Semken et al. (2017) reúnem diversos elementos que dizem respeito ao ensino baseado no lugar. Assinalam que sua importância para as Ciências da Terra se acha ligada a práticas educacionais cujos temas e conceitos partem do que é familiar aos estudantes e possibilitam relacionar ciências naturais e experimentais a outros modos de conhecer. Tudo isso, argumentam, atribui relevância e contexto para conceitos e práticas universais. 
uma abordagem que envolve alunos e professores em atividades de campo para construir e explorar hipóteses, construir caminhos de pesquisa, etc. as questões ambientais postas sob o ponto de vista do planeta (o ponto de vista geológico) trazem aportes inovadores e articulam aportes temporais e espaciais típicos das Ciências da Terra. ${ }^{?}$

O caminho perseguido ajudou a construir três módulos em torno de questões que envolvem o ambiente terrestre: o ciclo da água, o ciclo da areia e as transformações do ferro. Todos os módulos seguiram os mesmos eixos curriculares e princípios metodológicos. Cada um desses três módulos é composto por submódulos formulados de acordo com as situações locais adotadas e as características dos alunos. Isso ajudou a construir um amplo conjunto de materiais didáticos contextualizados pela cidade.

Um ponto alto foi o trabalho com os professores: eles foram os responsáveis por decidir o que ensinar, identificar os problemas cognitivos dos alunos e fazer um planejamento coletivo combinado à implementação individual. Entretanto, durante a implementação, um segundo professor manteve-se como observador para ajudar a aperfeiçoar o ensino e a aprendizagem, ou seja, a avalição do ensino foi uma atividade coletiva. A abordagem metodológica adotada se inspirou nas atividades de formação de professores preconizadas pela pesquisa ação acompanhando a conceituação de Elliott (2010).

O exercício e teste de diversos estudos de caso, acompanhados por sua avaliação coletiva, ajudou a despertar nos professores iniciativas voltadas para difundir as descobertas e promover a formação continuada. A partir de determinado momento, além de implementar as Ciências da Terra para alunos do ensino básico, os professores passaram a se envolver no processo de formação de outros professores. Nos limites deste texto, explora-se a aplicação de um módulo relativo às transformações do ferro para dois grupos distintos de professores: um para historiadores da ciência (Eletro-Metalúrgica Brasileira de Ribeirão Preto oficina para os participantes da VI Jornada de História da Ciência e Ensino, Juiz de Fora, Estado de Minas Gerais, 28-30 de setembro 2017), outro para professores de Química (Ciência do Sistema Terra: eixo con-

$7 \quad$ Fantinel (2005) descreve e caracteriza a atividade de campo em termos das ciências históricas que estudam a natureza. Kastens; Agrawal; Liben (2009) descreveram um experimento que examina a formação do raciocínio espacial por meio de atividade de campo. dutor de formação de professores para integração curricular - oficina promovida para os participantes do IX Encontro Paulista de Pesquisa em Ensino de Química, Sertãozinho, Estado de São Paulo, 18-20 outubro 2017).

O foco das duas oficinas foram as transformações do ferro exploradas a partir do empreendimento da Companhia de Força e Luz: a criação da Eletro-Metalúrgica Brasileira e especialmente a siderúrgica e aciaria Epitácio Pessoa (situada em Ribeirão Preto). O conceito central relacionado pelas duas oficinas é: Ferro: do Sol aos objetos de metal que pode ser compreendido como o conceito estruturante: $A$ Ciência atrás da siderurgia e da mineração do ferro.

\section{Descrição do módulo}

O módulo Ferro: do Sol aos objetos de metal foi o resultado de um desenvolvimento integrado promovido pela pesquisa conduzida por professores e pesquisadores de distintas áreas de conhecimento para explorar as ligações entre as Ciências da Terra e a formação de uma atitude cidadã diante do ambiente e do planeta.

Os objetivos desse módulo se acham associados ao desenvolvimento de raciocínios histórico-comparativos, sistêmicos e ligados à ampliação das dimensões e escalas temporais dos professores envolvidos. Professores que participam do módulo devem compreender os desafios naturais e culturais da previsão da mudança climática.

Os participantes são conduzidos a reconhecer que disciplinas diferentes podem ser integradas por meio de eixos temáticos que articulam História da Ciência, inovações tecnológicas e ambiente terrestre.

Guiado por princípios do Grupo de Pesquisa, o módulo se dirige para relações das Ciências da Terra e os desafios da mudança ambiental durante o tempo geológico, os participantes são engajados no pensamento interdisciplinar e utilizam raciocínios e métodos empregados pelos geólogos para tratar dados da história da Terra, dos elementos químicos, dos sistemas naturais e suas inter-relações sociais, econômicas e culturais. Trata-se de caminho para desenvolver raciocínios sistêmicos.

O ponto de partida do módulo é a história da Eletro-Metalúrgica Brasileira (siderúrgica que operou na década de 1920 em Ribeirão Preto). Na época, a região era um centro econômico agrícola importante e foi incentivada pelo governo federal a desenvolver a indústria mecânica pesada. Parti- 
cipantes são instigados a conhecer e descrever os passos importantes do empreendimento siderúrgico, suas necessidades de matérias primas (minas de ferro e calcário, bem como obtenção de carvão), meios de comunicação e transporte, financiamentos e incentivos governamentais. A partir dos balanços e fluxos econômicos, fluxos materiais se alcança a mineração de ferro (um depósito de ferro bandado de idade arqueana situado no sudoeste do Estado de Minas Gerais). Ver Figuras 1: foto da Usina Epitácio Pessoa; 2: foto do minério de ferro bandado de São Sebastião do Paraíso, MG e 3: foto do Morro do Ferro em São Sebastião do Paraíso.

O módulo indaga sobre as condições ambientais favoráveis à concentração do ferro bandado na crosta terrestre tanto em termos das hipóteses atualmente aceitas e seus vínculos com o desenvolvimento da vida na Terra, bem como a origem estrelar do elemento químico ferro no universo.

Dois obstáculos cognitivos sistêmicos são enfrentados pelo módulo. O primeiro revela que as grandes jazidas de ferro bandado da crosta terrestre não possuem origem magmática a partir de emanações do núcleo terrestre. $\mathrm{O}$ segundo põe em questão a mudança climática e revela que muitas causas e condições podem estar associadas à mudança climática atual, uma delas somente é causa antrópica.

Esses elementos são bastante esmiuçados por meio de materiais didáticos que foram elaborados e testados com alunos do ensino médio e permitem refinar muitos tópicos de distintos campos de conhecimento: histórico, químico, matemático, biológico e geológico. Os locais chaves são explorados (as ruínas

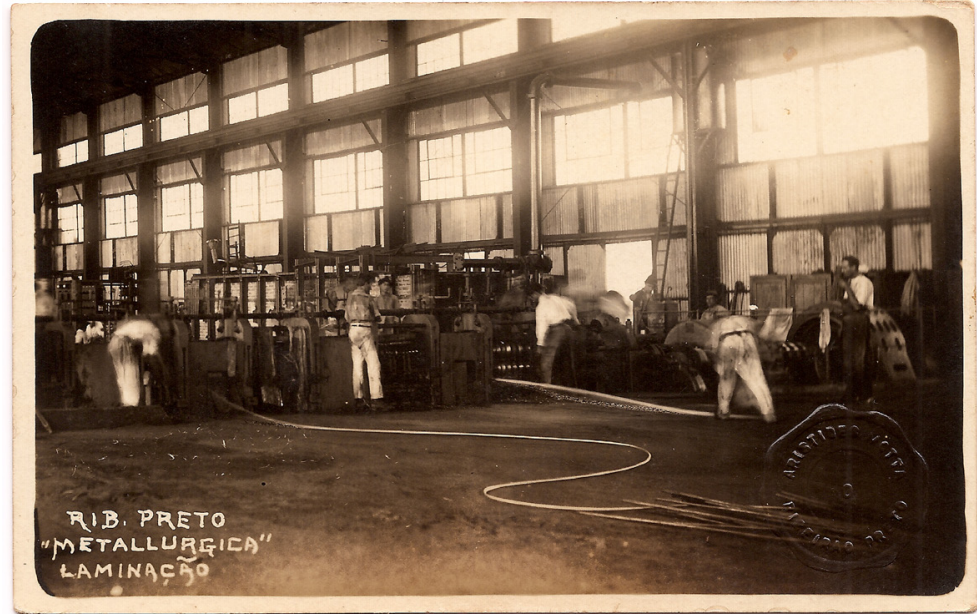

Figura 1. Usina Epitácio Pessoa, 1921, operários trabalhando na laminação. Fonte: Arquivo Público e Histórico de Ribeirão Preto. Fundo: Companhia de Força e Luz

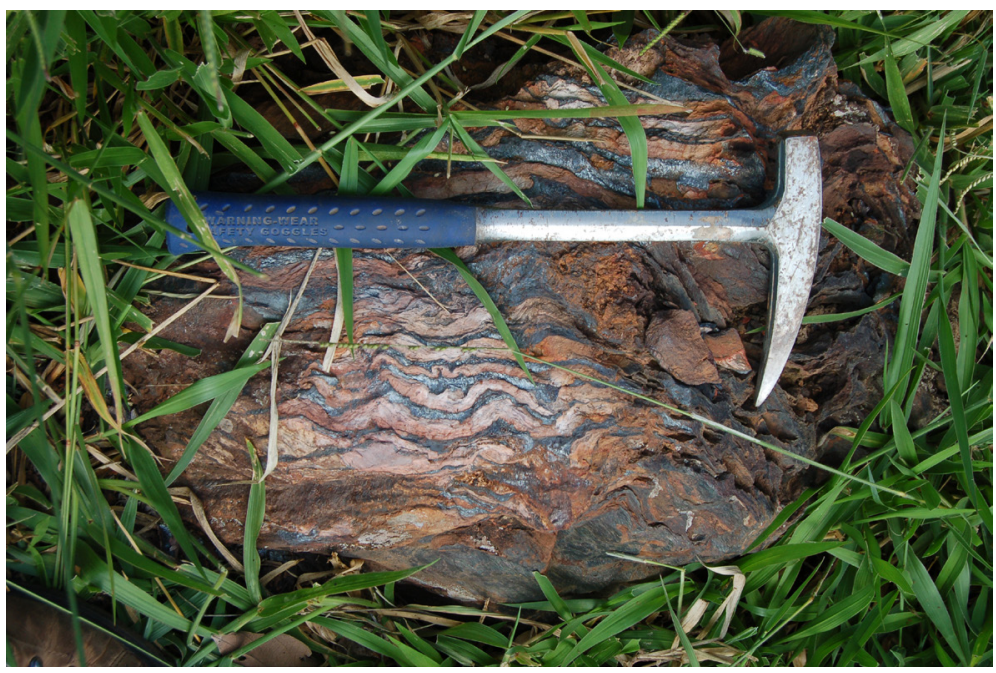

Figura 2. Amostra de minério de ferro bandado de São Sebastião do Paraíso, MG. Fonte: autores, visita em 2017

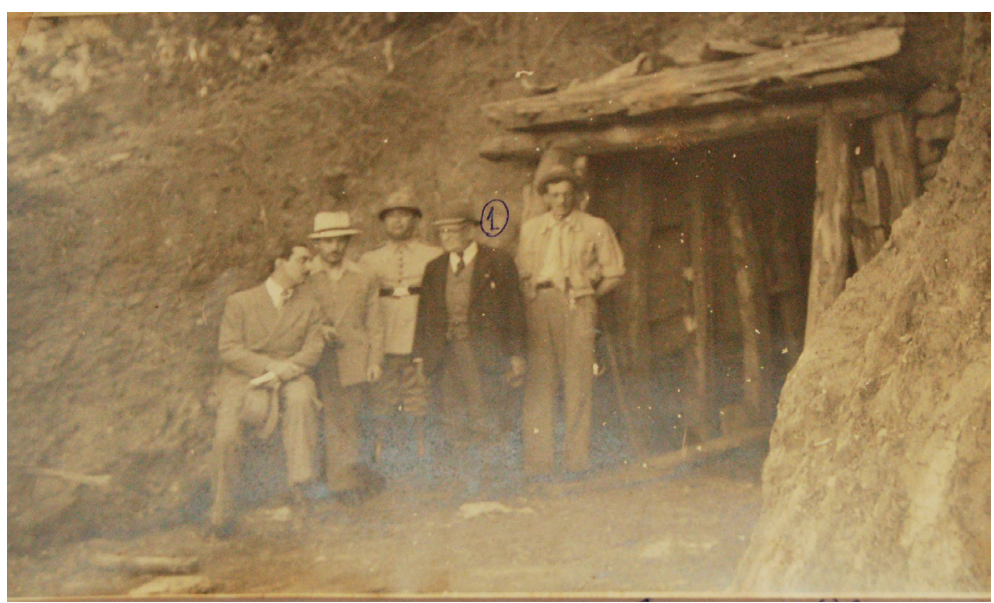

Figura 3. Morro do Ferro em São Sebastião do Paraíso, 1941. Inspeção policial à mina da falida Eletro Metalúrgica Brasileira. Fonte: Gentilmente cedida pelo advogado Luiz Ferreira Calafiori de São Sebastião do Paraíso

\begin{tabular}{c|c|c|c|c|c|c|}
\hline (C) Terrae Didat. & Campinas, SP & v.15 & $1-8$ & $\mathrm{e} 019030$ & 2019 \\
\hline
\end{tabular}


da antiga siderúrgica, bem como a mina de ferro abandonada). A História da Ciência desempenha um papel especialmente frutífero para revelar que na década de 1920 havia intensa disputa entre opções técnicas conflitantes para produção de ferro e aço (alto fornos elétricos, diferentes tipos de fornos, regióes do Brasil que deveriam ser priorizadas devido à produção de minério de ferro e carvão).

A Tabela 1 apresenta as questões chaves e os tópicos centrais que são explorados pelo módulo Ferro: do Sol aos objetos de metal.

O módulo possibilita que os professores participantes sintetizem informações históricas, químicas e de evolução biológica, climáticas e de mudança ambiental. Exploram-se evidências que podem ser usadas para avaliar a mudança climática global atualmente em curso e apreciar a interferência humana no processo. Serve, ainda, de ponto de partida para inspirar os participantes a promover atividades interdisciplinares regidas pelos mesmos eixos curriculares: ponto de partida no local e na cidade, teoria de sistemas e tempo geológico. Dessa maneira, trata-se de uma contribuição para a alfabetização ambiental dos professores.

Além disso, o intercâmbio com outros pro-

Tabela 1. Módulo Ferro: do Sol aos objetos de metal. Uma aproximação

Questões chaves
Se imaginarmos um "mundo" próximo
à superfície terrestre, uma espécie de vo-
lume que reúna a atmosfera, hidrosfera,
solos, rochas e seres vivos, em que locais
você identifica a presença da substância
ferro?

Qual é a diferença entre minério de ferro e aço?

Indique as etapas do ciclo do ferro.

\section{Tópicos centrais que são explorados}

Identificação de reservatórios importantes da substância ferro na região superficial da Terra.

Identificação das características do minério de ferro (substância iônica, geralmente um óxido ou sulfeto de ferro) e do aço (substância metálica, usualmente uma liga de ferro e carbono).

Caracterização do processo metalúrgico e reconhecimento de que a humanidade produz ferro e aço há aproximadamente 5.000 anos

Descrição de processos naturais pelos quais se dá a transformação de $\mathrm{Fe}^{2+}$ em $\mathrm{Fe}^{3+}$ e o inverso.

Reconhecimento de atividade bacteriana associada a tais transformações de oxirredução..

Sabemos que a porcentagem média de ferro em todos os minerais da crosta terrestre é de $5 \%$ (para se ter uma comparação, o oxigênio representa cerca de $50 \%$ ). Jazidas de ferro são locais onde a concentração de ferro é superior a $55 \%$ (locais que a concentração elevada permite a exploração econômica). Explique os mecanismos responsáveis pela concentração anômala de ferro das jazidas.

Discussão dos processos geológicos responsáveis pela acumulação de grandes quantidades de ferro bandado na crosta terrestre.

Descrição das diferentes hipóteses atualmente aceitas para explicar a formação do ferro bandado e as diversas possíveis contribuições de seres vivos diferentes nessa dinâmica.

Reconhecimento de que essa dinâmica foi importante somente no Arqueano e no Proterozoico. Reconhecimento de que as grandes jazidas de ferro bandado levaram centenas de milhões de anos para se formar. Reconhecer as características básicas das jazidas brasileiras de ferro do Quadrilátero Ferrífero e de Carajás.

Reconhecimento de condições ambientais profundamente diferentes das atuais (efeito estufa muito mais intenso e ausência de oxigênio na atmosfera e hidrosfera).

Por que a Eletro-Metalúrgica Brasileira foi instalada em Ribeirão Preto, Estado de São Paulo (considerando que as jazidas de ferro estavam em São Sebastião do Paraíso, Estado de Minas Gerais)?
Reconhecimento da necessidade de diversificação de aplicação do capital acumulado a partir da agricultura (ampliação das ferrovias e da indústria no interior paulista).

Reconhecimento da existência de padrões técnicos divergentes e conflitantes em termos de: altos-fornos (elétrico ou a carvão), tipo de carvão a ser empregado (vegetal ou mineral), localização da siderúrgica (próximo das minas de ferro e carvão ou, próximo dos mercados consumidores). 
fessores do ensino básico traz a possibilidade de refletir sobre os princípios metodológicos que regem o Grupo de Pesquisa: desenvolver o ensino em cooperação com os estudantes, buscar fontes de informação além do material mais tradicional (arquivo histórico, técnicos, moradores, etc.) e extrapolando o espaço intramuros. Isso é coerente com uma atitude investigativa, perseguidora de novas informações e novas reflexões.

\section{Discussão}

Os professores participantes do módulo se defrontaram com problemas complexos e com discussões históricas, biológicas e geológicas que estão postas no meio acadêmico nos últimos cem anos. Os precários dados históricos da Eletro-Metalúrgica Brasileira e os modelos evolutivos do Arqueano ajudam a formar raciocínios sistêmicos, narrativos e hipotéticos.

Os participantes têm oportunidade de interagir e discutir dentro de uma abordagem realista. Dessa forma, se preparam para o estudo, reflexão e debate sobre questões ambientais.

Pode-se alegar que o número de professores participantes na aplicação do módulo (uma vez em Juiz de Fora, outra em Sertãozinho) é pequeno e, portanto, não representativo do conjunto de professores. Argumentamos que não pretendemos construir propostas universais para formar professores de Ciências da Terra. De fato, pretendemos mostrar que os eixos, princípios e conceitos integradores servem de exemplo e inspiração para que outros professores percebam possibilidades insuspeitas de ensino. Como os eixos curriculares foram testados com estudantes do ensino médio, eles foram adaptados para ajudar a formar professores.

Johnson, Kahle \& Fargo (2009) apresentam um instrumento de avaliação qualitativa do envolvimento de participantes no processo de ensino. $\mathrm{O}$ uso desse instrumento com os participantes das duas oficinas indica que a instrução foi efetiva porque todos os participantes se engajaram nas discussões, além de manipular ativamente os materiais didáticos durante o período de trabalho.

\section{Conclusões}

Ciência do Sistema Terra serviu como eixo integrador de diferentes componentes curriculares. Ao orientar eixos curriculares e princípios metodológicos investigativos facilitou que professores do nível básico pudessem identificar locais e questões da cidade para construir processos educativos interdisciplinares. Os princípios serviram para elaborar um módulo destinado à formação de professores para Ciências da Terra em torno das transformações da substância ferro. O módulo Ferro: do Sol aos objetos de metal reuniu as investigações anteriores e propiciou avanços nas reflexões dos professores participantes sobre o ensino.

Os professores do Grupo de Pesquisa estão continuamente sendo formados por meio da pesquisa colaborativa. Eles desenvolvem e testam conteúdos novos, aprendem a reelaborar e reconstruir o currículo. Adquirem maior autonomia e confiança com o currículo em ação explorando a integração feita por meio das Ciências da Terra. O ganho de qualidade dos professores é o indicador de sucesso dos princípios metodológicos adotados.

\section{Referências}

Carneiro, C. D. R., Toledo, M. C. M. de, \& Almeida, F. F. M. de, (2004). Dez motivos para inclusão de temas de Geologia na educação básica. Revista Brasileira de Geociências, 34.4, 553-560. doi: 10.25249/0375-7536.2004344553560.

Cervato, C. \& Frodeman, R. (2014). A importância do tempo geológico: desdobramentos culturais, educacionais e econômicos. Terre Didatica, 10.1, 67-79. doi: 10.20396/td.v10i1.8637389.

Elliott, J. (2010). El 'estudio de la enseñanza y del aprendizaje': una forma globalizadora de investigación del profesorado, Revista Interuniversitaria de Formación de Profesorado, 24.2, 223-242.

Fantinel, L. M. (2005). O ensino de mapeamento geológico no Centro de Geologia Eschwege, Diamantina - MG: análise de três décadas de práticas de campo (19702000). Tese de Doutorado, Universidade Estadual de Campinas, Campinas, Brasil.

Gimeno Sacristán, J. (2000). O currículo: uma reflexão sobre a prática. Porto Alegre: Artmed.

Gonçalves, P. W. (1997). A luz invisível: o conceito de analogia na doutrina natural e moral de James Hutton. Tese de doutorado, Universidade Estadual de Campinas, Campinas, Brasil.

Gonçalves, P. W. (2001). Projeto de Pesquisa- Ensino de Ciência do Sistema Terra mediante formação de professores em efetivo exercício. Departamento de Geociências Aplicadas ao Ensino. Instituto de Geociências, Universidade Estadual de Campinas, Campinas.

Gonçalves, P. W. (2011). Memorial Pedro Wagner Gonçalves. Memorial destinado ao Concurso de Livre Docência da Área de Ciências da Terra (Disciplinas Ciência do Sistema Terra I e II, Elementos de Geologia). Universidade Estadual de Campinas,

\begin{tabular}{c|c|c|c|c|c}
\hline (C) Terrae Didat. & Campinas, SP & v.15 & $1-8$ & $\mathrm{e} 019030$ & 2019 \\
\hline
\end{tabular}


Instituto de Geociências, Campinas

Gonçalves, P. W.; \& Sicca, N. A. L. (2005a). O Que os Professores Pensam Sobre Geociências e Educação Ambiental? (Levantamento Exploratório de Concepções de Professores de Ribeirão Preto, SP), Geologia USP, Publ. Espec., 3, 97-106.

Gonçalves, P. W.; \& Sicca, N. A. L. (2005b). Didática de Ciências da Terra: cidade e ambiente como focos para o ensino médio. Anais da $28^{\mathrm{a}}$ Reunião Anual da ANPED (Associação Nacional de Pós-Graduação e Pesquisa em Educação), Caxambú, MG, Brasil, 1-16.

Gonçalves, P. W.; \& Sicca, N. A. L. (2008). Como a inovação curricular contribui para a autonomia do professor? Anais $31^{a}$ Reunião Anual da ANPED (Associação Nacional de Pós-Graduação e Pesquisa em Educação), Caxambú, MG, Brasil, 1-15.

Johnson, C. C., Kahle, J. B. \& Fargo, J. D. (2009). Effective Teaching Results in Increased Science Achievement for All Students. Science Education, 91.3, 371-383.

Kastens, K. A., Agrawal, S. \& Liben, L. S. (2009). How Students and Field Geologists Reason in Integrating Spatial Observations from Outcrops to Visualize a 3-D Geological Structure, International Journal of Science Education, 31.3, 365-393.

Lacreu, H. L.(2009). Recursos geoambientales y cidadania. Actas do IV Simpósio Nacional sobre Ensino de Geologia no Brasil (on Cd-Rom).

Mayer, V. J. (2002). Global Science Literacy: a theoretical and conceptual foundation for science curricula, In: Mayer, V. J. (ed.) Implementing Global Science
Literacy (v. 2, chapter 1, p. 5-22). Columbus, Ohio: The Ohio State Univ.

Pedrinaci E., Alcalde S., Alfaro P., Almodóvar G.R., Barrera J. L., Belmonte Á, Brusi D., Calonge A., ... \& Roquero E. 2013. Alfabetización en Ciencias de la Tierra. Rev. de la Enseñanza de las Ciencias de la Tierra, 21(2):117-129. URL: http://www.raco. cat/index.php/ECT/article/view/274145/362238. Acesso 29.01.2019.

Rossi, P. (1984). The dark abyss of time: the history of the Earth and the history of nations from Hooke to Vico. Chicago: The University of Chicago Press.

Semken, S.; Ward, E. G.; Moosavi S.; \& Chinn, P. W. U. (2017). Place-Based Education in Geoscience: Theory, Research, Practice, and Assessment, Journal of Geosciences Education, 65.4, 542-562. doi: https://doi.org/10.5408/17-276.1.

Shipley, T. F.; McConnell, D.; McNeal, K. S.; Petcovic, H. L. \& St. John, K. E. (2017). Transdisciplinary Science Education Research and Practice: Opportunities for GER in a Developing STEM Discipline-Based Education Research Alliance (DBER-A), Journal of Geosciences Education, 65.4, 354-362. doi:10.5408/1089-9995-65.4.354.

Sicca, N. A. L.; Gonçalves, P. W.; Fernandes, M. C. S. G.; Alves, M. A. R.; Canesin, M. B. S.; Santos, M. J. dos; La Corte, M. M. A. de;\& Figueiredo, R. L. (2014). Interfaces currículo do ensino médio e Geociências: 10 anos de reflexões de grupo de pesquisa colaborativa, Terre Didatica, 10.3, 357-367. URL: https://periodicos.sbu.unicamp.br/ojs/index.php/ td/article/view/8637353/5060. 